\title{
The Impact of Longevity Risk on the Optimal Contribution Rate and Asset Allocation for Defined Contribution Pension Plans
}

\author{
Sharon S. Yang a and Hong-Chih Huang ${ }^{\mathrm{b}}$ \\ ${ }^{a}$ Department of Finance, National Central University, 300 Road, Tao-Yuan, Taiwan. \\ E-mail: syang@ncu.edu.tw \\ ${ }^{\mathrm{b}}$ Department of Risk Management and Insurance, National Cheng Chi University, 64, Section 2 , \\ Chi-Nan Road, Taipei, Taiwan. \\ E-mail: jerry2@nccu.edu.tw
}

This research studies the interaction between longevity risk and asset allocation for a defined contribution pension plan. We investigate the investment strategy during the accumulation phase to deal with longevity risk during the decumulation phase. The longevity risk is demonstrated using the U.K. mortality experience for pensioners. We experiment with three patterns of mortality: base, projection and stochastic mortality rates. The optimal asset allocation and contribution rate are determined by minimizing the variance of the error between the value of pension fund and required pension fund plus the square of the expected value of the error. The required pension fund is decided by the pension fund target, measured using the income replacement ratio. We consider four assets in the asset allocation and observe four types of changes to the rebalancing investment strategies. The results show a life cycle investment strategy and indicate that longevity risk can be hedged by either raising the contribution rate or setting a more aggressive asset allocation.

The Geneva Papers (2009) 34, 660-681. doi:10.1057/gpp.2009.18

Keywords: longevity risk; asset allocation; income replacement ratio

\section{Introduction}

Defined contribution (DC) pension plans have become popular in the global pension market because recent increases in longevity have increased pressures on defined benefit (DB) pension plan providers. The main difference between DB and DC pension plans pertains to the way they treat financial risk. In a DC plan, the member bears the financial risk, so whether that individual receives a good pension depends on his or her investment strategy. In contrast, for a DB plan, the retirement benefit is promised in advance according to some predetermined formulae. Thus, employers bear the risks of poor investment performance by the pension fund. The study of the asset allocation problem for DC pension plans has emerged as an important research topic.

Investment strategies to address financial risk in DC plans have been widely explored. ${ }^{1}$ Blake et al. ${ }^{2}$ study asset risk and estimate values-at-risk in the accumulation

\footnotetext{
${ }^{1}$ Blake et al. (2001); Vigna and Haberman (2001); Haberman and Vigna (2002); Battocchio and Menoncin (2004); Raimond et al. (2007).

2 Blake et al. (2001).
} 
phase of DC pension plans by examining a range of asset-return models. Vigna and Haberman $^{3}$ and Haberman and Vigna ${ }^{4}$ both study asset risk, and Haberman and Vigna $^{5}$ further consider downside risk in the asset allocation strategy. Battocchi and Menoncin ${ }^{6}$ note two background risks: salary risk and inflation risk in pension management. Maurer et al. ${ }^{7}$ also study optimal life cycle strategies in the presence of interest rate and inflation risk under a stochastic framework. These studies all investigate the investment strategy during the accumulation phase and consider financial risks including asset risk, salary risk, inflation risk and interest rate risk. Other research pertaining to the decumulation period focus on the choice or time of annuitisation and thus neglect longevity risk. ${ }^{8}$

However, other than financial risk, longevity entails the greatest risk faced by individual pensioners in DC plans, because life expectancy is dramatically increasing. ${ }^{9}$ Willets et al. ${ }^{10}$ analyse changes in mortality and find that life expectancy at retirement in the U.K. is likely to increase rapidly in the 21 st century. For a DC plan with the benefit paid in the form of an annuity, the benefits provided depend on not only the investment strategy but also the price of the annuity at retirement. Longevity risk is the risk of future uncertainty with a long-term trend of mortality improvement, which will lead to a low conversion rate used to buy the annuity at retirement. For the retiree, longevity risk may involve losing a financial resource because the retirement benefit might not be sufficient to last for the rest of his or her life.

Dealing with the uncertainty of future mortality trends in a pension fund or annuity products thus constitutes an important issue and the purpose of this work. The study of longevity risk and asset allocation has not received the same focus as financial risk, with a few exceptions. ${ }^{11}$ Hainaut and Devolder ${ }^{12}$ address mortality and financial risks for DB pension plans instead of DC plans, and Charupat and Milevsky ${ }^{13}$ analyse the interaction between financial risk and mortality risk and derive the optimal asset allocation in the pay-out phase for a variable annuity contract. Battocchio et al. ${ }^{14}$ study the asset allocation under mortality risk during the accumulation and decumulation phases. They assume a Gompertz-Makeham mortality model to represent the remaining lifetime of the member.

Unlike Charupat and Milevsky ${ }^{15}$ or Battocchio et al.,${ }^{16}$ we consider a more realistic mortality experience to illustrate the impact of longevity risk on the optimal

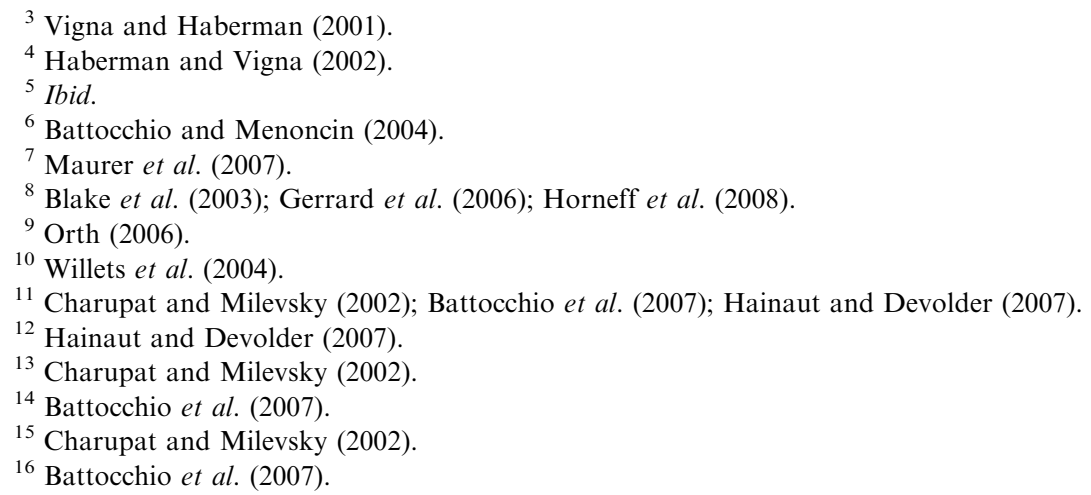


contribution rate and asset allocation for a DC plan. This investigation of longevity risk uses the U.K. mortality experience for pensioners. In addition to longevity risk, we consider asset risk, salary risk and inflation risk, and provide a stochastic framework to determine the optimal asset allocation and contribution rates. The optimal asset allocation depends on the asset liability matching criteria. The liability is determined by the pension fund target, measured using the income replacement ratio (RR). We set the objective function for the individual to minimise the variance of the simulated sample path with the asset liability matching criteria. In other words, we minimise the risk that a person will be unable to reach his or her retirement target.

In the U.K., increased longevity has been dramatic in recent decades and caused severe financial problems for pension fund providers and annuity providers, such as Equitable Life, that issue guaranteed annuity options. ${ }^{17,18}$ In practice, the Continuous Mortality Investigation Bureau (CMIB), which has responsibility for the production and publication of standard mortality tables in the U.K., uses reduction factors to project future mortality. ${ }^{19}$ The actuary prices the annuity value according to the projected mortality table. However, there may be a risk that the mortality projections turn out to be wrong, and modelling uncertainty associated with future mortality trends has become very important for the retirement system. In addition, CMIB ${ }^{20}$ conducted a follow-up study to investigate the stochastic projection methodologies of the Lee-Carter model, whereas Lee ${ }^{21}$ and Yang $^{22}$ set out stochastic mortality rates using Kalman filter-like processes based on the projected mortality rates to analyse the problem of guarantee annuity options. Other stochastic mortality models have been widely explored. ${ }^{23}$ Pitacco $^{24}$ describes some aspects of the development of survival modelling in actuarial mathematics, with a special emphasis on issues pertaining to longevity risk. Cairns et $a l^{25}$ in particular demonstrate that the inclusion of a cohort effect can provide a better fit, using data from England, Wales and the U.S.

This study of the impact of longevity risk on asset allocation strategies for a DC pension plan considers the investment strategy during the accumulation phase that employees use to deal with longevity risk during the decumulation phase. We consider four assets in the asset allocation and observe four types of changes to the rebalancing strategies. To assess an investment strategy, we measure the tracking error. The asset dynamics are modelled using Wilkie's ${ }^{26}$ investment model. We investigate the effects of longevity risk with three patterns of mortality: base mortality rate, projected mortality rate and stochastic mortality rate. The base rate and projected mortality derive from

${ }^{17}$ Guaranteed annuity options offer policyholders the right to convert the sum assured at normal retirement age into a life annuity at the better market rate prevailing at the time of conversion and a guaranteed rate. This option involves both morality and interest rate risk.

${ }^{18}$ Ballotta and Haberman (2003, 2006); Boyle and Hardy (2003); Pelsser (2003); Wilkie et al. (2003).

${ }^{19}$ CMIB (1999), Renshaw and Haberman (2000, 2003).

${ }^{20}$ CMIB (2007).

${ }^{21}$ Lee (2000).

${ }^{22}$ Yang (2001).

${ }^{23}$ Milevsky and Promislow (2001); Cairns et al. (2004b).

${ }^{24}$ Pitacco (2004).

${ }^{25}$ Cairns et al. (2007).

${ }^{26}$ Wilkie's (1995). 
the recent CMIB's mortality tables for the pensioners. Finally, we incorporate Lee's ${ }^{27}$ and Yang's ${ }^{28}$ models to project the future stochastic mortality rate and model longevity risk.

The remainder of this article is organised as follows: the following section describes the model settings for a DC pension plan. We present the investment strategies and objective functions for finding the optimal asset allocation in the subsequent section then explain how to model longevity risk in the section following it. In the penultimate section, we compute the optimal contribution rate and asset allocation for three patterns of mortality. We conclude and suggest future research directions in the final section.

\section{A model for DC pension plans}

We design a DC pension plan that includes two phases: an accumulation phase and a decumulation phase. In the accumulation phase, the employee contributes a constant proportion of his or her salary to a personal pension fund. In the decumulation phase, the pension fund gets converted into an annuity at the time of retirement.

\section{Accumulation phase}

Assume that an employee joins the pension scheme at age $x$ and retires at age $x+n$. The employee pays contributions yearly in advance, equal to a fixed percentage of his or her salary. The level of the employee's pension fund at retirement depends on factors such as the level of contribution, age at entry, retirement age and investment earnings. Let $F(t)$ denote the level of the pension fund at time $t$, expressed as follows:

$$
F(t)=[F(t-1)+C(t)] \times \sum_{i=1}^{k} p_{i}(t-1)\left(1+r_{i}(t-1)\right),
$$

where $C(t)$ is the contribution at time $t$, such that $C(t)=c \% \cdot S_{x+t-1}, c \%$ is the constant contribution rate, $S_{x+t}$ is the annual salary at age $x+t, p_{i}(t)$ is the proportion of funds invested in the $i$ th asset during year $[t, t+1], r_{i}(t)$ is the investment return of the $i$ th asset in year $[t, t+1]$, and $k$ is the number of assets.

\section{Decumulation phase}

In the decumulation phase, the pension fund at the time of retirement is converted into a life annuity. According to the equivalence principle, the amount of annuity is calculated as:

$$
\text { Annuity }=\frac{F(n)}{\ddot{a}_{x+n}},
$$

\footnotetext{
${ }^{27}$ Lee (2000).

${ }^{28}$ Yang (2001).
} 
where $\ddot{a}_{x+n}$ is the value of an annuity of one per annum payable annually in advance for life, after the member attains retirement age $x+n$. The value of $\ddot{a}_{x+n}$ is determined by the assumptions of interest rates and mortality rates.

\section{Pension fund target}

We attempt to find the optimal asset allocation and contribution rate of a DC pension fund to meet the individual's pension fund target and study the impact of longevity risk on the optimal asset allocation and contribution rate. The pension fund target is measured by the income RR, defined as the ratio of the annuity payment to the final salary for a person joining the pension plan at age $x$ and retiring at age $x+n$, or

$$
R R_{n}=\frac{\text { annuity }}{S_{x+n-1}},
$$

where $S_{x+n-1}$ is the final year's salary before retirement.

The pension fund target represents the percentage of income required to maintain a desired standard of living for the person during his or her retirement years. According to the pension fund target, we can calculate the corresponding required pension fund at retirement $\bar{F}(n)$ as follows:

$$
\bar{F}(n)=R R_{n} \times S_{x+n-1} \times \ddot{a}_{x+n} .
$$

Therefore, we attempt to find the optimal asset allocation to meet a specific amount of $\bar{F}(n)$. To study the effect of longevity risk, we reflect the dynamics of mortality to calculate the annuity factor and the corresponding required pension fund.

\section{Investment strategy and asset allocation}

\section{Objective function}

To find the optimal asset allocation to meet the individual's pension fund target at retirement, we set the objective function to minimise the variance of the simulated sample path with the asset liability matching criteria, which is

$$
\begin{gathered}
\operatorname{Min}_{c \%, p_{i}(t)}\left\{\operatorname{Var}[\bar{F}(n)-F(n)]+(\mathrm{E}[\bar{F}(n)-F(n)])^{2}\right\} \\
=\operatorname{Min}_{c \%, p_{i}(t)}\left\{\mathrm{E}\left[(\bar{F}(n)-F(n))^{2}\right]\right\} \\
\text { s.t. }\left\{\begin{array}{c}
\sum_{i=1}^{k} p_{i}(t)=1 \\
0 \leqslant p_{i}(t) \leqslant 1 \quad \forall i=1,2, \ldots, k .
\end{array}\right.
\end{gathered}
$$

Thus, we propose to minimise the risk that a person will be unable to reach his or her retirement target. Several researchers employ this objective function, including 
Wise, ${ }^{29}$ Sherris, ${ }^{30}$ Wilkie, ${ }^{31}$ and Huang and Cairns. ${ }^{32}$ The optimal contribution rate and asset allocations emerge from a simulation approach. To find the optimal contribution rate and asset allocations, we solve the optimisation problem in the objective function using Matlab programming. ${ }^{33}$

\section{Investment strategies}

Investment strategies for a pension fund involve a long period. We cannot ignore the inflation risk. In addition to long-term bonds, short-term bonds and stocks - the traditional elements of a pension fund portfolio - we consider index-linked gilt. ${ }^{34}$ Thus, we consider four assets in the investment strategy for pension funds. To examine the impacts of longevity risk in the U.K. pension market, we employ Wilkie's ${ }^{35}$ investment model to project the dynamics of future asset returns and the salary growth rate. The advantage of Wilkie's model is that it uses a range of financial indicators, including retail price inflation, share dividend yields, bond yields, long-term bonds and short-term bonds. In addition, it projects the dynamic of salary growth. The parameters of Wilkie's investment model have been estimated using U.K. financial data. The financial econometrics of Wilkie's investment model appear in Appendix. Blake et $a l .{ }^{36}$ examine a range of asset-return models to assess the model risk for a DC pension fund including Wilkie's investment model. In this research, we attempt to study the impact of longevity risk on the optimal asset allocation. Thus, we illustrate our numerical example using only Wilkie's investment model. The question of model risk is not addressed in this research.

Asset allocations for pension funds indicate long-term investment decisions. We therefore investigate the effect of an investment strategy on the asset allocation decision and consider a rebalancing investment strategy, which rebalances the pension fund portfolio at regular durations. In other words, the proportion of each asset remains constant during each duration. In this case, are more frequent rebalancing periods during the accumulation phase beneficial? To answer this question, we examine four investment strategies:

Investment strategy 1: Changing the proportion of the pension fund portfolio every 5 years.

Investment strategy 2: Changing the proportion of the pension fund portfolio every 10 years.

\footnotetext{
${ }^{29}$ Wise (1984).

${ }^{30}$ Sherris (1992).

${ }^{31}$ Wilkie (1995).

${ }^{32}$ Huang et al. (2006).

33 The optimal solutions are solved by Matlab7.0 with function "fmincon".

${ }^{34}$ Index-linked gilts differ from conventional gilts in that both the semi-annual coupon payments and the principal payment are adjusted in line with movements in the General Index of Retail Prices (also known as the RPI).

${ }^{35}$ Wilkie (1995).

${ }^{36}$ Blake et al. (2001).
} 
Investment strategy 3: Changing the proportion of the pension fund portfolio every 20 years.

Investment strategy 4: Keeping a fixed proportion of the pension fund portfolio set during the accumulation period.

Incorporating these different investment strategies, we can express the accumulation of pension fund at retirement as follows.

$$
\begin{aligned}
F(n)= & (F(n-1)+C(n))\left[\sum_{j=1}^{4} P_{j}(n) \times\left(1+r_{j}(n)\right)\right] \\
= & F(n-1)\left[\sum_{j=1}^{4} P_{j}(n) \times\left(1+r_{j}(n)\right)\right]+C(n)\left[\sum_{j=1}^{4} P_{j}(n) \times\left(1+r_{j}(n)\right)\right] \\
= & (F(n-2)+C(n-1))\left[\sum_{j=1}^{4} P_{j}(n-1) \times\left(1+r_{j}(n-1)\right)\right] \\
& \times\left[\sum_{j=1}^{4} P_{j}(n) \times\left(1+r_{j}(n)\right)\right]+C(n)\left[\sum_{j=1}^{4} P_{j}(n) \times\left(1+r_{j}(n)\right)\right] \\
= & \ldots \\
= & \sum_{t=1}^{n} C(t) \prod_{i=t}^{n}\left[\sum_{j=1}^{4} P_{j}(i) \times\left(1+r_{j}(i)\right)\right]
\end{aligned}
$$

The pattern of asset allocations for the different investment strategies can be studied and their performance assessed using tracking errors.

\section{Modelling longevity risk}

To understand the impact of longevity risk on the contribution rate and asset allocation, we employ actuarial mortality experiences for pensioners from the U.K. According to the CMIB's mortality tables for the pensioners, we consider three patterns of mortality: base, projected and stochastic mortality rates. The base mortality rate represents the expected assumptions and does not consider the effect of mortality improvements, whereas the projected and stochastic mortality rates include the effect of mortality improvements. We use the stochastic mortality rate to investigate the longevity risk. In this research, the base mortality rates are demonstrated using the most recent mortality table for pensioners of PMA92. ${ }^{37}$ The projected mortality rates are modelled using reduction factors based on 37 The PMA92 denotes the mortality tables for annuity and pension businesses based on data from 1991 to
1994 (CMIB, 1998, 1999). The construction of PMA92 mortality table is introduced in Subsection 4.1 . 
$\mathrm{CMIB},{ }^{38}$ which is denoted as PMA92C2020 ${ }^{39}$ For the stochastic rates, we consider the uncertainty in modelling the reduction factor and use the Kalman filter-like process proposed by Lee ${ }^{40}$ and Yang. ${ }^{41}$ The methodology for the construction of the base mortality rate (PMA92), projected mortality rates (PMA92C2020) and stochastic mortality rates appear next.

\section{Base mortality rates}

The methodology to calculate the base mortality rates $\left(q_{x}\right)$ for pensioners in CMIB is as follows:

$$
\begin{aligned}
q_{x} & =1-p_{x} \\
& =1-\exp \left[-\int_{0}^{1} \mu_{x+s} d s\right],
\end{aligned}
$$

where $\mu_{x}$ and $p_{x}$ denote the force of mortality and the survival probability for a person aged $x$, respectively. According to the PMA92 mortality table CMIB, ${ }^{42} \mu_{x}$ can be calculated as:

$$
\mu_{x}=G M(r, s)(t), \text { with } r=2 \text { and } s=3,
$$

where $\operatorname{GM}(2,3)(t)=a_{1}+a_{2} t+\exp \left[b_{1}+b_{2}+b_{3}\left(2 t^{2}-1\right)\right]$,

$$
\begin{aligned}
100 a_{1} & =0.023, \\
100 a_{2} & =-0.011, \\
b_{1} & =-5.397782, \\
b_{2} & =6.622746 \text { and } \\
b_{3} & =-1.6 .
\end{aligned}
$$

\section{Projected mortality rates}

In U.K. actuarial practice, the CMIB uses the reduction factor to model the future mortality rate. Thus, the base table must be calculated first, then applied to the improvement factor to obtain the projected mortality rates, given by:

$$
q_{x, t}=q_{x} \times R F_{x, t} .
$$

where $q_{x}$ denotes the mortality rate for age $x$ according to the base table, $q_{x, t}$ is the projected probability of death within 1 year for a person of age $x$ at time $t$, and $R F_{x, t}$ is

\footnotetext{
38 CMIB (1999).
}

39 PMA92C2020 denotes the projected mortality rates for the calendar year of 2020 based on PMA92 tables. The CMIB uses the reduction factor to project future mortality rate. The construction of reduction factor for PMA92C2020 mortality table is introduced in Subsection 4.2.

${ }^{40}$ Lee (2000).

41 Yang (2001).

42 CMIB (1999). 
the projected mortality improvement factor for age $x$ at time $t$. The CMIB's ${ }^{43}$ calculation of the reduction factors is based on a 20 -year time span, according to the mortality experience of $1991-1994,{ }^{44}$ which is

$$
R F_{x . t}=\alpha(x)+[1-\alpha(x)] \times[1-f(x)]^{t / 20}
$$

where

$$
\begin{aligned}
a(x) & =c \leqslant 60 \\
& =1+(1-c) \frac{x-10}{110 / 50} \quad 60 \leqslant x \leqslant 110 \\
& =1 \quad x \geqslant 110,
\end{aligned}
$$

and

$$
\begin{aligned}
f(x) & =h \quad x \leqslant 60 \\
& =\frac{(110-x) h+(x-60) / k}{50} \quad 60 \leqslant x \leqslant 110 \\
& =k \quad x \geqslant 110,
\end{aligned}
$$

The corresponding parameters are $c=0.13, h=0.55$ and $k=0.29$.

In this research, we use the reduction factor to project mortality rates for the calendar year 2020 from the PMA92 tables, which is denoted as PMA92C2020. In Figure 1, we depict the survival probability trend for pensioners aged 65 years, according to the a(55), ${ }^{45}$ PA90M, PMA80C2010 and PMA92C2020 mortality tables. The most recent table, PMA92C2020, reveals a significant improvement over the a(55) table, which provides an upper bound on the mortality improvements. In addition, the significant projection changes between the 1967 and 1970 mortality rates and that based on 1991 and 1994 data indicates that even the best-constructed forecasts may prove wrong. To deal with this issue, we might allow future mortality rates to be random. We employ the Lee and Yang model, which we discuss next.

\section{Lee and Yang's stochastic mortality model}

Due to the problem of the deterministic mortality table, Lee ${ }^{46}$ and Yang $^{47}$ derive stochastic mortality rates to model actual mortality rates, given the expected mortality

43 Ibid.

44 PMA92 mortality table.

45 The a(55), PA90M, PMA80C2010 and PMA92C2020 mortality tables, which relate to annuity and pension businesses, are constructed differently. The a(55) table, constructed in 1955, is the oldest mortality estimation (CMIB, 1978); the PA90M table uses data from 1967 to 1970; and PMA80C2010 uses data from 1979 to 1982 (CMIB, 1988, 1990) and projects mortality rates for the calendar year 2010 from the PMA80 tables. Finally, PMA92C2020 is the most recent, based on data from 1991 to 1994 (CMIB, 1998, 1999) and projects mortality rates for the calendar year 2020 from the PMA92 tables.

${ }^{46}$ Lee (2000).

47 Yang (2001). 


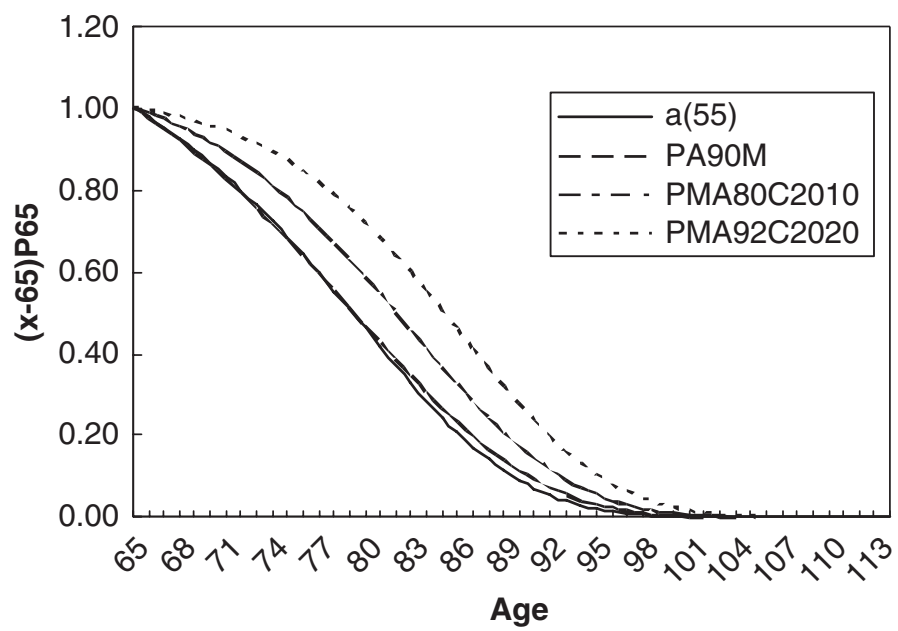

Figure 1. Survival probability trends for British people older than 65 years of age from the a(55), PA90M, PMA80C2010 and PMA92C2020 mortality tables. (Note: ${ }_{x-65} p_{65}$ is the survival probability that a person aged 65 years will attain age $x$.)

rates from the projected tables. Specifically, Lee ${ }^{48}$ develops a feasible stochastic mortality model, and Yang ${ }^{49}$ modifies and uses that model to analyse a guaranteed annuity option. Cairns et al. ${ }^{50}$ name this stochastic mortality model the Lee and Yang model.

The Lee and Yang model assumes two random variables: $X(t)$ and $Y(t) . X(t)$ captures the permanent changes in mortality and performs a random walk with a zero mean, whereas $Y(t)$ describes the transient changes in mortality in each year and depends on $X(t)$. That is,

$$
X(t)=X(t-1)+Z_{X}(t) \quad \text { and } \quad Y(t)=X(t)+Z_{Y}(t),
$$

where $Z_{X}(t)$ and $Z_{Y}(t)$ are independent and follow $\mathrm{ND}\left(0, \sigma_{X}^{2}\right)$ and $\mathrm{ND}\left(0, \sigma_{Y}^{2}\right)$, respectively. In the Lee and Yang model, the actual mortality rates $\left(\hat{q}_{x, t}\right)$ for a person aged $x$ in year $t$ are assumed to be

$$
\hat{q}_{x, t}=q_{x, t} \cdot \exp \left[Y(t)-\frac{1}{2} t \sigma_{X}^{2}-\frac{1}{2} \sigma_{Y}^{2}\right] .
$$

This assumption makes the projected mortality rate $\left(q_{x, t}\right)$ an unbiased estimate of the future actual mortality rate $\left(\hat{q}_{x, t}\right)$, which is provided by CMIB. To determine the impact of longevity risk on the optimal contribution rate and asset allocation, we

\footnotetext{
${ }^{48}$ Lee (2000).

49 Yang (2001).

${ }^{50}$ Cairns et al. (2004b).
} 
calculate the value of a life annuity under a stochastic mortality rate environment to reflect the level of pension funds needed to meet the pension fund target.

\section{Simulation output}

In the numerical observation, we investigate the investment strategy in a DC pension plan and the impact of longevity risk on optimal asset allocations and optimal contribution rates. The asset allocation suggested by the base mortality rate represents the benchmark and does not consider the effect of mortality improvements, whereas the asset allocations that rely on projected and stochastic mortality rates include mortality improvements. We use the stochastic mortality rate to investigate the longevity risk. The parameters used for the stochastic mortality model are those estimated by Yang, ${ }^{51}$ namely $\sigma_{x}=0.044$ and $\sigma_{y}=0$. We also consider the dynamics of asset returns and the salary growth rate using Wilkie's investment model; the parameters are those estimated by Wilkie ${ }^{52}$ (see ). In the following investigation, we set 80 per cent of the income RR as the pension fund target. Assume the employee starts working at age 25 and retires at age 65 for the base illustration case. The initial yearly salary is one unit and the salary growth rate follows the setting of Wilkie's model.

\section{Optimal asset allocation with base mortality table}

We first investigate the optimal contribution rate and asset allocation with base mortality rates. Tables 1-4 indicate the results of different investment strategies; in all cases, the majority proportion of the optimal asset allocation is invested in indexlinked gilt, because salary growth is relative to the inflation rate in the setting of Wilkie's investment model. To hedge the inflation risk, the individual must invest more in the index-linked gilt. The optimal asset allocation shows that the proportion invested in short-term bonds and index-linked gilt increases as employees approach their retirement. In contrast, the proportion invested in long-term bonds decreases as employees near retirement. In other words, the employee invests money more aggressively in the beginning of the accumulation period and then more conservatively with time. The results are consistent with findings in Vigna and Haberman, ${ }^{53}$ Haberman and Vigna, ${ }^{54}$ and Cairns et al. ${ }^{55}$ Cairns et al., ${ }^{56}$ in their investigation of stochastic lifestyle asset allocation using three assets, observe that the equity fund dominates the investment strategy, but as a person's retirement date approaches, he or she gradually switches from high-risk to low-risk funds. Their findings support our results.

\footnotetext{
51 Yang (2001).

52 Wilkie (1995).

53 Vigna and Haberman (2001).

${ }^{54}$ Haberman and Vigna (2002).

${ }^{55}$ Cairns et al. (2004a).

${ }^{56}$ Ibid.
} 
Table 1 Optimal asset allocation and contribution rate for investment strategy 1 with base mortality table

\begin{tabular}{lrrrrrrrr}
\hline Asset classes & \multicolumn{7}{c}{ Time to change asset allocation } \\
\cline { 2 - 9 } & \multicolumn{1}{c}{0} & 5 & 10 & 15 & 20 & 25 & 30 & 35 \\
\hline Short-term bond (\%) & 0 & 0 & 0 & 0 & 1.07 & 2.29 & 3.80 & 24.23 \\
Long-term bond (\%) & 100 & 44.63 & 31.45 & 18.90 & 14.99 & 11.75 & 8.89 & 0 \\
Index-linked gilt (\%) & 0 & 51.39 & 68.55 & 80.31 & 83.94 & 85.73 & 87.31 & 73.00 \\
Stock (\%) & 0 & 3.98 & 0 & 0.79 & 0 & 0.23 & 0 & 2.77
\end{tabular}

Optimal contribution rate $=16.55 \%$.

Tracking error $=360.55$.

Table 2 Optimal asset allocation and contribution for investment strategy 2 with base mortality table

\begin{tabular}{lcccc}
\hline Asset classes & \multicolumn{4}{c}{ Time to change asset allocation } \\
\cline { 2 - 5 } & 0 & 10 & 20 & 30 \\
\hline Short-term bond (\%) & 0 & 1.40 & 4.56 & 17.86 \\
Long-term bond (\%) & 49.61 & 21.19 & 10.83 & 0 \\
Index-linked gilt (\%) & 50.39 & 77.41 & 84.50 & 80.05 \\
Stock (\%) & 0 & 0 & 0.11 & 2.09 \\
\hline
\end{tabular}

Optimal contribution rate $=16.58 \%$.

Tracking error $=384.45$.

Table 3 Optimal asset allocation and contribution for investment strategy 3 with base mortality table

\begin{tabular}{lcr}
\hline Asset classes & \multicolumn{2}{c}{ Time to change asset allocation } \\
\cline { 2 - 3 } & \multicolumn{2}{c}{20} \\
\hline Short-term bond (\%) & 1.62 & 13.91 \\
Long-term bond (\%) & 20.77 & 1.30 \\
Index-linked gilt (\%) & 77.61 & 83.41 \\
Stock $(\%)$ & 0 & 1.37
\end{tabular}

Optimal contribution rate $=16.37 \%$.

Tracking error $=404.23$.

In assessing the performance of different investment strategies, if we change the rebalancing proportions more frequently, the person in general holds more long-term bonds at the beginning of the accumulation period to gain higher returns. When employees approach retirement, they switch and hold more short-term bonds to reduce their liquidity risk. The optimal contribution rate is not very sensitive to the investment strategy but tracking error is. ${ }^{57}$ To meet the 80 per cent income RR of the

${ }^{57}$ The tracking error is the expected quadratic difference between the accumulated asset cash flows and the accumulated liability cash flows at a fixed time horizon. 
Table 4 Optimal asset allocation and contribution for investment strategy 4 with base mortality table

\begin{tabular}{lr}
\hline & Static investment strategy \\
\hline Short-term bond (\%) & 13.06 \\
Long-term bond (\%) & 2.12 \\
Index-linked gilt (\%) & 84.79 \\
Stock (\%) & 0.03 \\
\hline
\end{tabular}

Optimal contribution rate $=16.37 \%$.

Value of objective function $=421.24$.

pension fund target, the optimal contribution rates for investment strategies $1-4$ are 16.55 per cent, 16.58 per cent, 16.37 per cent and 16.37 per cent, respectively but the tracking error changes significantly over the four strategies, from 360.55 to 384.45 to 404.23 and finally to 421.24 for investment strategy 4 . Therefore, more frequent changes to the rebalancing proportion can improve target liability matching.

\section{Impact of longevity risk on optimal asset allocation}

In this subsection, we consider how to change the optimal asset allocation to deal with longevity risk when the contribution rate is predetermined. ${ }^{58}$ To investigate the effect of longevity, we set the same contribution rate of 16.55 per cent ${ }^{59}$ but with different mortality assumptions. Figure 2 presents the optimal asset allocations with different mortality assumptions for investment strategy 1 during the accumulation period (40 years). The optimal asset allocation changes from the base to projecting the stochastic mortality rate and suggests putting more money in riskier assets. For example, the proportion invested in stocks obviously increases with the stochastic mortality assumption. Thus, the individual hedges life uncertainty with riskier assets. The effects of investment strategy 1 also apply to investment strategies $2-4$. For simplicity, we do not repeat the figures for these investment strategies.

In addition to the impact on optimal asset allocations, we address the tracking error of different investment strategies in Figure 3. When considering the longevity risk in asset allocation, employees become more aggressive, which results in larger tracking error. According to the stochastic mortality table, the tracking error increases from 963.0 to $2,208.64$ for investment strategy 1 , from $1,011.7$ to $2,207.58$ for investment strategy 2, from $1,055.9$ to $2,242.1$ for investment strategy 3 and from 1,097.6 to 2,306.3 for investment strategy 4 .

\section{Impact of the working period on the results}

In the previous investigation, we assumed the employee started working at age 25 and retired at age 65 , which means the working period was of 40 years. In this section, we

\footnotetext{
${ }^{58}$ Longevity risk might be hedged by raising the contribution rate or changing asset allocation. In this research, we show the effect of longevity risk on optimal asset allocation.

5916.55 per cent is the optimal contribution rate calculated by the base mortality assumption.
} 


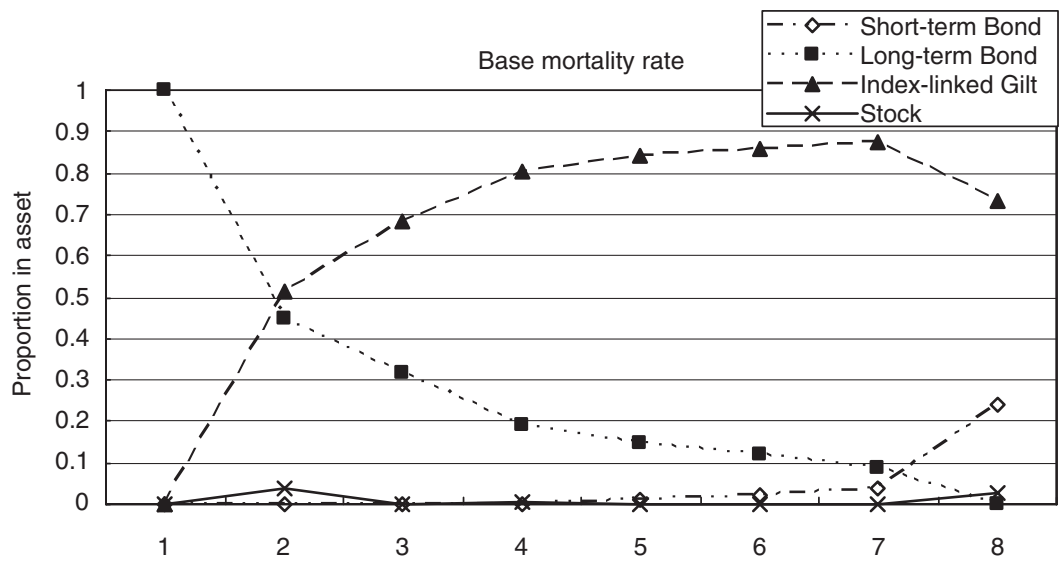

The ith times of changing asset allocation

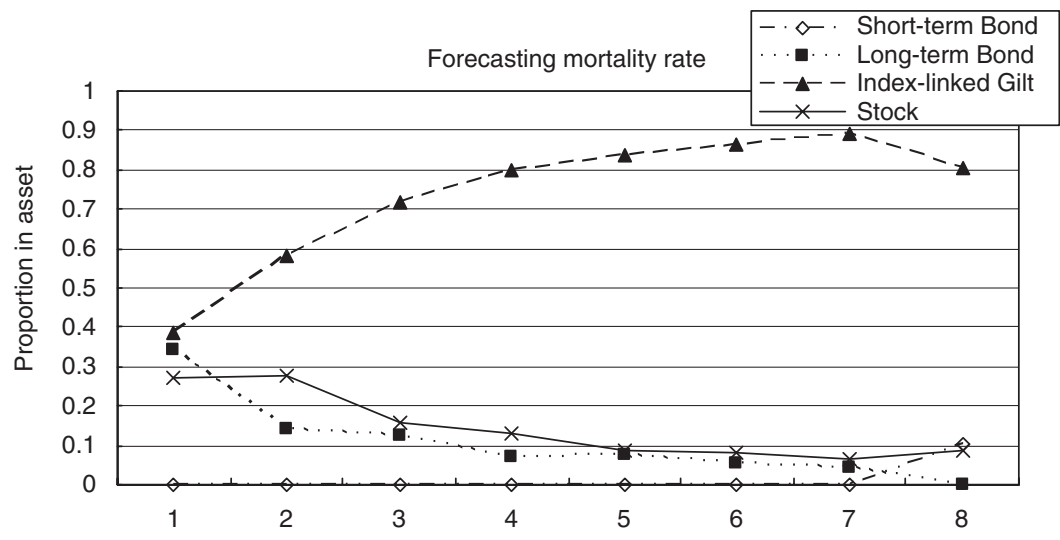

The ith times of changing asset allocation

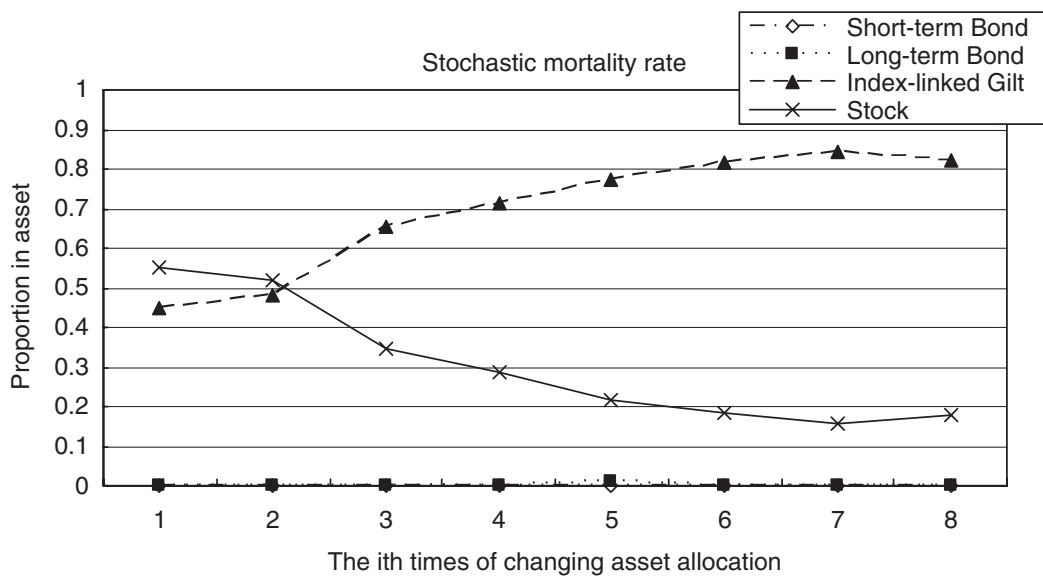

Figure 2. Comparison of optimal asset allocations during the accumulation period (40-year duration) for investment strategy 1 based on three patterns of mortality. 


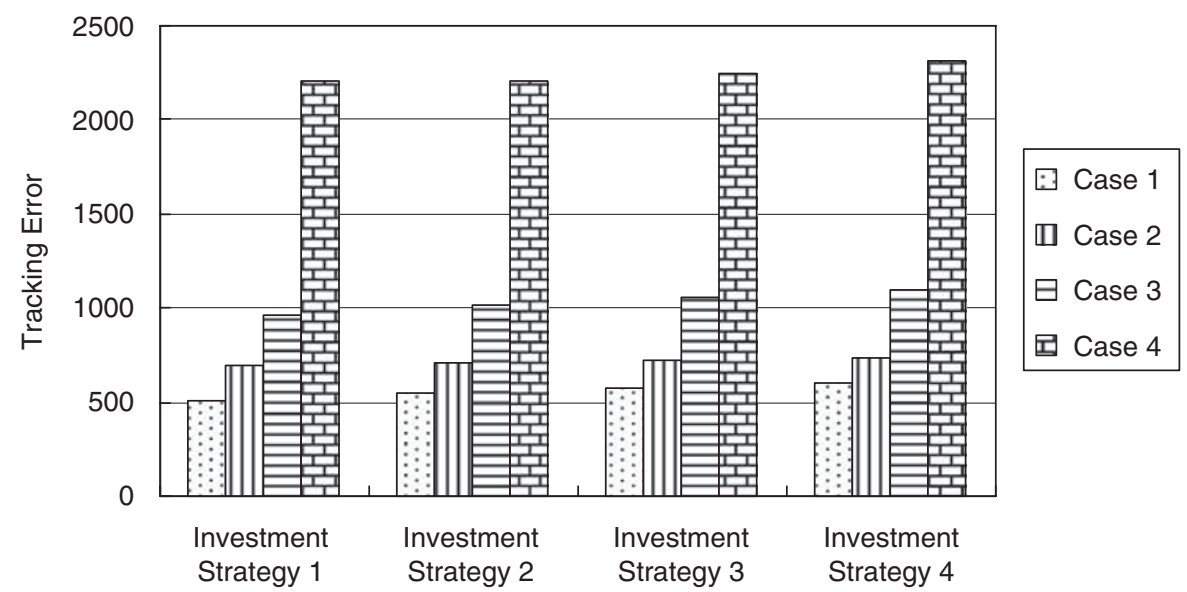

Figure 3. Tracking error comparison (age 25 years). Notes: Case 1: Projecting mortality table; optimal contribution rate. Case 2: Projecting mortality table; deterministic contribution rate. Case 3: Stochastic mortality table; optimal contribution rate. Case 4: Stochastic mortality table; deterministic contribution rate.

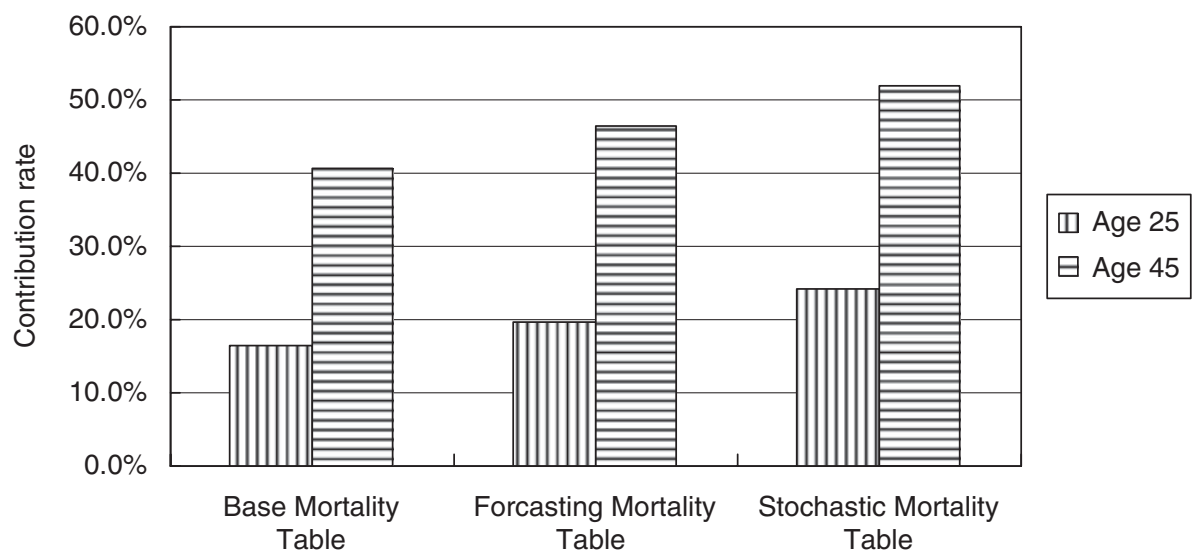

Figure 4. Comparison of contribution rate.

assume the employee starts working at age 45 and retires at age 65 to assess the impact of a shorter working period (i.e. 20 years).

The corresponding results of the contribution rates for employees starting at age 45 appear in Figure 4. The contribution rate increases from 16.55 per cent to 40.70 per cent according to the base mortality rates, from 19.76 per cent to 46.48 per cent with the forecasting mortality rates, and from 24.26 per cent to 51.92 per cent under the stochastic mortality assumption. These results are intuitive: the employee must raise the contribution rate to meet the pension retirement target faster for a shorter working period. 


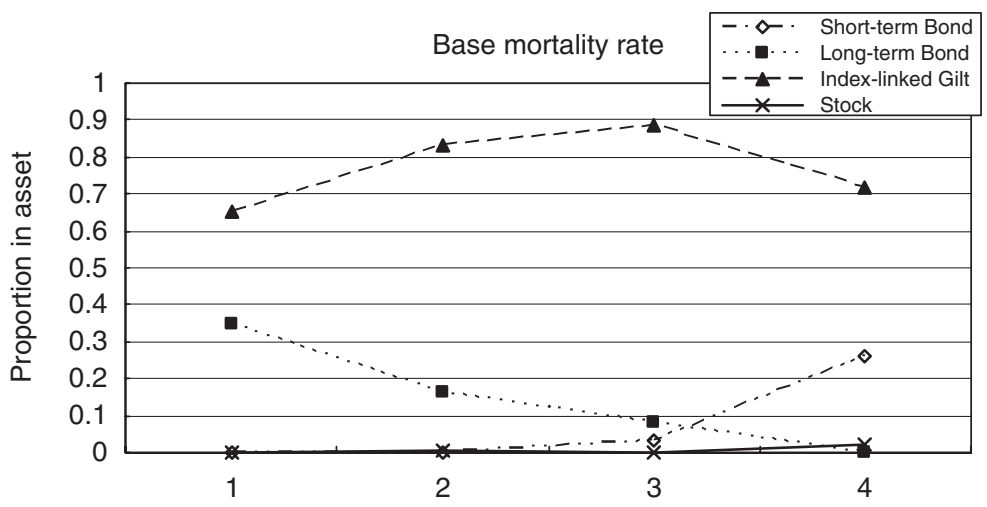

The ith times of changing asset allocation
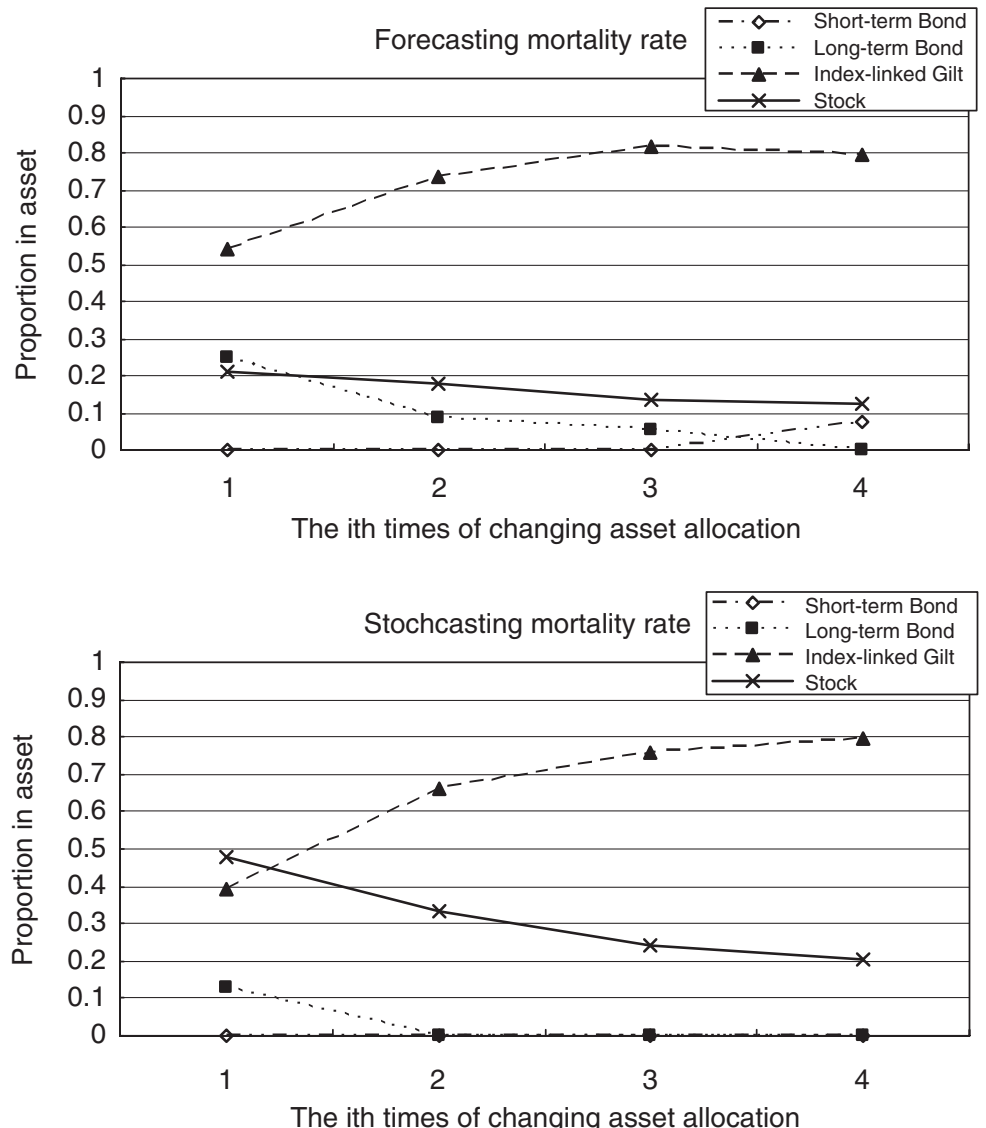

Figure 5. Comparison of optimal asset allocations during the accumulation period (20-year duration) for investment strategy 1 based on three patterns of mortality. 
The impacts of the working period on the optimal asset allocation appear in Figure 5. Similar to our preceding conclusion, the employee increases the contribution rate to accelerate the pension fund accumulation to meet the target faster. In addition, the optimal asset allocation for a shorter working period with the different mortality assumptions increases the proportion invested in stocks compared with results for a 40-year duration.

\section{Conclusions}

Asset allocation for DC pension plans is critical to employees, because the pension they receive depends entirely on investment performance. For example, the recent global financial crisis had great impacts on employees with DC pension plans, especially those approaching retirement age. The crisis has highlighted the dangers of leaving pension money invested freely in financial markets. Thus, the asset allocation to deal with the financial risk should be considered for employees in the DC pension plan.

Significant literature has addressed financial risk, including asset, salary and inflation risks in the asset allocation problem. However, longevity risk has become ever more important due to increasing life expectancy trends worldwide. The effect of longevity risk is systematic, so it has caused significant financial pressures on pension funds and annuity providers. This pressure can explain the dramatic increase in DC pension plans in recent years. For the employee, longevity risk might mean running out of available resources during retirement. In recent years, research on the asset allocation problem has gained greater attention from researchers who investigate the interaction between longevity risk and asset allocation for pension funds. ${ }^{60}$

In this research, in addition to asset, salary and inflation risk, we consider longevity risk in the asset allocation problem. Unlike current literature, we consider a more realistic mortality experience to study the impact of longevity risk. We also demonstrate the longevity risk using actuarial mortality experience for pensioners from the U.K. The effect of longevity risk is illustrated with three patterns: base, projected and stochastic mortality rates, according to the structure of CMIB mortality tables for pensioners. We develop a stochastic framework that includes asset, salary and mortality dynamics to determine the optimal asset allocation and contribution rates and to study the effect of longevity risk. The objective function meets the employee's income RR, which enables us to minimise the variance of the simulated sample path with the asset liability matching criteria. We consider four assets in the asset allocation and observe four rebalancing strategies.

The results show that longevity risk can be hedged by either raising the contribution rate or setting more aggressive asset allocations. With the objective function to minimise the variance with the asset liability matching criteria, we find that the employee shows a life cycle investment strategy. To compare the performance of different investment strategies, more frequent rebalancing can improve target liability

\footnotetext{
${ }^{60}$ Charupat and Milevsky (2002); Battocchio et al. (2007); Hainaut and Devolder (2007).
} 
matching. These findings apply both when we consider and when we ignore longevity risk in the asset allocation. However, the effect is more significant when we consider longevity risk. Specifically, when we take longevity risk into account, the asset allocation is more aggressive when we do not increase the contribution rate.

This article therefore responds to two issues in DC pension research. First, we propose a stochastic framework that considers future uncertainty to find the optimal asset allocation. Second, the proposed life cycle investment strategy can protect the employee from both financial risk and longevity risk when approaching retirement in the DC plan. In addition, our research might be extended in several ways. First, other objective functions could be investigated, or the employee's attitude toward risk might be taken into account. Second, the development of stochastic mortality models is very important to deal with longevity risk. A wide range of mortality models have been proposed and discussed. ${ }^{61}$ The effect of model risk on the result is worth determining. Third, we note that the methodology of analysing longevity risk is applicable to other life annuity products and DB pension plans, so further research should attempt such applications.

\section{References}

Ballotta, L. and Haberman, S. (2003) 'Valuation of guaranteed conversion rate', Insurance: Mathematics and Economics 33: 87-108.

Ballotta, L. and Haberman, S. (2006) 'The fair valuation problem of guaranteed annuity options: The stochastic mortality environment case', Insurance: Mathematics and Economics 38(1): 195-214.

Battocchio, P. and Menoncin, F. (2004) 'Optimal pension management in a stochastic framework', Insurance: Mathematics and Economics 34(1): 79-95.

Battocchio, P., Menoncin, F. and Scaillet, O. (2007) 'Optimal asset allocation for pension funds under mortality risk during the accumulation and decumulation phases', Annals of Operations Research 152(1): $141-165$.

Blake, D., Cairns, A.J.G. and Dowd, K. (2001) 'Pensionmetrics: Stochastic pension plan design and value-at-risk during the accumulation phase', Insurance: Mathematics and Economics 29: 187-215.

Blake, D., Cairns, A.J.G. and Dowd, K. (2003) 'Pensionmetrics: Stochastic pension plan design and value-at-risk during the distribution phase', Insurance: Mathematics and Economics 33: $29-47$.

Boyle, P. and Hardy, M. (2003) 'Guaranteed annuity options', ASTIN Bulletin 33(2): 125-152.

Cairns, A.J.G., Blake, D. and Dowd, K. (2004a) Stochastic lifestyling: Optimal dynamic asset allocation for defined contribution pension plans, working paper.

Cairns, A.J.G., Black, D. and Dowd, K. (2004b) Pricing death: Frameworks for the valuation and securitization of mortality risk, working paper.

Cairns, A.J.G., Blake, D., Dowd, K., Coughlan, G.D., Epstein, D., Ong, A. and Balevich, L. (2009) 'A quantitative comparison of stochastic mortality models using data from England and Wales and the United States', North American Actuarial Journal 13(1): 1-35.

Charupat, N. and Milevsky, M.A. (2002) 'Optimal asset allocation in life annuities: A note', Insurance: Mathematics and Economics 30(2): 199-209.

CMIB (1978) Proposed standard tables for life office pensioner and annuitants, Continuous Mortality Investigation Reports, Faculty of Actuaries and Institute of Actuaries, Edinburgh and London (3): $1-31$.

CMIB (1988) The graduation of the 1979-82 mortality experience, Continuous Mortality Investigation Reports, Faculty of Actuaries and Institute of Actuaries, Edinburgh and London (9): 1-103.

\footnotetext{
${ }^{61}$ For example Cairns et al. (2009).
} 
CMIB (1990) Standard tables of mortality based on the 1979-1982 experience, Continuous Mortality Investigation Reports, Faculty of Actuaries and Institute of Actuaries, Edinburgh and London (9): $1-138$.

CMIB (1998) Proposed new tables for life office pensioner, normal, male and female, based on the 1991-94 experience, Continuous Mortality Investigation Reports, Faculty of Actuaries and Institute of Actuaries, Edinburgh and London (16): 113-142.

CMIB (1999) Graduation of the 1991-94 Mortality Experience - The "92" Series Standard Tables, Continuous Mortality Investigation Reports, Faculty of Actuaries and Institute of Actuaries, Edinburgh and London (17): 1-229.

CMIB (2007) Continuous mortality investigation life office mortality committee, Stochastic projection methodologies: Lee-Carter model features, example results and implications, working paper 25.

Gerrard, R., Habberman, S. and Vigna, E. (2006) 'The management of decumulation risks in a defined contribution pension plan', North American Actuarial Journal 10(1): 84-110.

Haberman, S. and Vigna, E. (2002) 'Optimal investment strategy and risk measures in defined contribution pension schemes', Insurance: Mathematics and Economics 31: 35-69.

Hainaut, D. and Devolder, P. (2007) 'Management of a pension fund under mortality and financial risks', Insurance: Mathematics and Economics 41(1): 134-155.

Horneff, W.J., Maurer, R.H., Mitchell, O.S. and Dus, I. (2008) 'Following the rules: Integrating asset allocation and annuitization in retirement portfolios', Insurance: Mathematics and Economics 42(1): 396- 408

Huang, H.C., Cairns, A.J.G. (2006) 'On the control of defined-benefit pension plans', Insurance: Mathematics and Economics 38: 113-131.

Lee, P.J. (2000) A General Framework for Stochastic Investigations of Mortality and Investment Risks, paper presented at the Wilkiefest, Heriot-Watt University, Edinburgh.

Milevsky, M.A. and Promislow, S.D. (2001) 'Mortality derivatives and the option to annuities', Insurance: Mathematics and Economics 29: 299-318.

Orth, B.J. (2006) 'Managing longevity risk in U.S. retirement plans through mandatory annuitization', North American Actuarial Journal 10(3): 32-44.

Pelsser, A. (2003) 'Pricing and hedging guaranteed annuity options via static option replication', Insurance: Mathematics and Economics 33: 283-296.

Pitacco, E. (2004) 'Survival models in a dynamic context: A survey', Insurance: Mathematics and Economics 35: 279-298.

Raimond, H., Maurer, C.S. and Michael, Z.S. (2007) Optimal life-cycle strategies in the presence of interest rate and inflation risk, Pension Research Council working paper, Pension Research Council.

Renshaw, A.E. and Haberman, S. (2000) Modelling for mortality reduction factors, Actuarial Research Paper no. 127, City University, London.

Renshaw, A.E. and Haberman, S. (2003) 'On the forecasting of mortality reduction factors', Insurance: Mathematics and Economics 32(3): 379-401.

Sherris, M. (1992) 'Portfolio selection and matching: A synthesis', Journal of the Institute of Actuaries 119(I): $87-105$.

Vigna, E. and Haberman, S. (2001) 'Optimal investment strategy for defined contribution pension schemes', Insurance: Mathematics and Economics 28: 233-262.

Wilkie, A.D. (1986) 'A stochastic asset model for actuarial use', Transactions of the Faculty of Actuaries 39: $341-381$.

Wilkie, A.D. (1995) 'More on a stochastic asset model for actuarial use', British Actuarial Journal 1: 777-964.

Wilkie, A.D., Waters, H.R. and Yang, S.S. (2003) 'Reserving, pricing and hedging for policies with guaranteed annuity option', British Actuarial Journal 9(2): 263-391.

Willets, R.C., Gallop, A.P., Leandro, P.A., Lu, J.L.C., Macdonald, A.S., Miller, K.A., Richards, S.J., Robjohns, N., Ryan, J.P. and Waters, H.R. (2004) 'Longevity in the 21st century', British Actuarial Journal 10(5): 1027-1045.

Wise, A.J. (1984) 'The matching of assets to liabilities', Journal of the Institute of Actuaries 111(Part II): 445-501.

Yang, S.S. (2001) Reserving, pricing and hedging for guaranteed annuity option, PhD dissertation, Heriot-Watt University, Edinburgh. 


\section{Appendix}

Wilkie's investment model was first introduced in 1986, with an updated version presented in 1995. In the 1995 version, Wilkie updated the parameter values used in the original model and extended the model to cover short-term interest rates, the yield on long-dated index-linked gilts, property rental yields, the force of property rental growth and the force of salary growth. We only introduce the series used in this article; see Wilkie ${ }^{62}$ for more details.

The force of inflation rate: The force of inflation rate $(I(T))$ is an $A R(1)$ model, as follows:

$$
I(T)=Q M U+Q A[I(T-1)-Q M U]+Q E(T),
$$

where $Q M U$ is the mean force of inflation, $Q A$ is the parameter controlling the strength of the autoregression, and $Q E(T)$ is an i.i.d. random white noise term distributed Normal $\left(0, Q S D^{2}\right)$. The estimated parameters suggested by Wilkie ${ }^{63}$ are

$$
Q M U=0.047, Q A=0.58, Q S D=0.0425 .
$$

The force of earnings inflation: The model of the force of earnings inflation $J(t)$ is

$$
J(t)=W W 1 \times I(t)+(1-W W 1) \times I(t-1)+W N(t)
$$

with

$$
W N(t)=W M U+W A[W N(t-1)-W M U]+W E(t)
$$

where $W Z(t)$ is an i.i.d. random white noise term distributed Normal $\left(0, W S D^{2}\right)$. The estimated parameters suggested by Wilkie ${ }^{64}$ are

$$
Q M U=0.047, Q A=0.58, Q S D=0.0425 .
$$

$W W 1=0.69, W M U=0.016, W A=0.0, W S D=0.0244$

Long-term gilt yield: The model of the long-term gilt yields $(C(T))$ at time $T$ as

with

$$
C(T)=C W \times C M(T)+C M U \times \exp [C N(T)],
$$

$$
\begin{aligned}
& C M(T)=C D \times I(T)+(1-C D) \times C M(T-1) \text { and } \\
& C N(T)=C A \times C N(T-1)+C Y \times Y E(T)+C E(T),
\end{aligned}
$$

\footnotetext{
${ }^{62}$ Wilkie (1995)

${ }^{63}$ Ibid.

${ }^{64}$ Ibid.
} 
where $C E(T)$ is an i.i.d. random white noise term distributed Normal $\left(0, C S D^{2}\right), Y E(\mathrm{~T})$ is as defined below, and the values of the estimated parameters suggested by Wilkie ${ }^{65}$ are

$$
\begin{aligned}
C W & =1.0, \quad C M U=0.0305, \quad C D=0.045, \quad C A=0.8974, \\
C Y & =0.3371, \quad C S D=0.1853 .
\end{aligned}
$$

Short-term cash rate: The model of the short-term cash rate $(B(T))$ at time $T$ is

$$
B(T)=C(T) \times \exp [-B D(T)],
$$

with

$$
B D(T)=B M U+B A \times(B D(T-1)-B M U)+B E(T),
$$

where $B E(T)$ is an i.i.d. random white noise term distributed Normal $\left(0, B S D^{2}\right)$ and the values of the estimated parameters suggested by Wilkie ${ }^{66}$ are

$$
B A=0.74, \quad B M U=0.23, \quad B S D=0.18 .
$$

Share dividend yield: The share dividend yield $(Y(T))$ has two components: a term related to the inflation rate and an $A R(1)$ model for $Y N(T)$, as follows:

with

$$
Y(T)=Y M U \times \exp [Y W \times I(T)+Y N(T)],
$$

$$
Y N(T)=Y A \times Y N(T-1)+Y E(T),
$$

where $Y E(T)$ is an i.i.d. random white noise term distributed Normal $\left(0, Y S D^{2}\right)$. The estimated parameters suggested by Wilkie ${ }^{67}$ are

$$
Y W=1.8, \quad Y M U=0.0375, \quad Y A=0.55, \quad Y S D=0.155 .
$$

Yield on long-dated index-linked gilts: The model of the yield on long-dated indexlinked gilts $R(t)$ is

$$
\ln R(t)=\ln R M U+R A \times[\ln R(t-1)-\ln R M U]+R B C \times C E(t)+R E(t)
$$

where $R E(T)$ is an i.i.d. random white noise term distributed Normal $\left(0, R S D^{2}\right)$. The estimated parameters suggested by Wilkie ${ }^{68}$ are

$$
Z M U=0.074, \quad Y A=0.91, \quad Y S D=0.12 .
$$

Share dividend index: The share dividend index $(D(T))$ at time $t$ is

$$
\begin{aligned}
D(T)= & D(T-1) \times \exp [D Q(T)+D M U \\
& +D Y \times Y E(T-1)+D B \times D E(T-1)+E D(T)],
\end{aligned}
$$

\footnotetext{
${ }^{65}$ Wilkie (1995)

${ }^{66} \mathrm{Ibid}$.

${ }^{67} \mathrm{Ibid}$.

${ }^{68}$ Ibid.
} 
with

$$
\begin{aligned}
& D Q(T)=D X \times Q(T)+(1-D X) \times D M(T) \text { and } \\
& D M(T)=D D \times I(T)+(1-D D) \times D M(T-1),
\end{aligned}
$$

where $D E(T)$ is an i.i.d. random white noise term distributed Normal $\left(0, D S D^{2}\right)$. The estimated parameters suggested by Wilkie ${ }^{69}$ are

$$
\begin{aligned}
D M U & =0.016, \quad D Y=-0.175, \quad D B=0.57, \quad D X=0.42, \\
D D & =0.13, \quad D S D=0.07 .
\end{aligned}
$$

Share price index: The share price index $(P(T))$ can be derived from the dividend index and the dividend yield, as follows:

$$
P(T)=D(T) / Y(T) .
$$

\section{About the Authors}

Sharon S. Yang is Associate Professor of Finance at National Central University, Taiwan. Her research interests cover pension and insurance product valuation, stochastic mortality modelling and risk management for equity-linked insurance.

Hong-Chih Huang is Associate Professor of Risk Management and Insurance at National ChengChi University University, Taiwan. His research interests cover asset liability management for pension fund and insurance product, and stochastic mortality modelling. 